\title{
Student performativity in higher education: converting learning as a private space into a public performance
}

\author{
Bruce Macfarlane* \\ Faculty of Education, The University of Hong Kong, Hong Kong SAR
}

\begin{abstract}
The paper sets out a conceptual analysis of student performativity in higher education as a mirror image of teacher performativity. The latter is well known and refers to targets, evaluations and performance indicators connected with the measurement of the teaching and research quality of university academics. The former is defined as the way that students are evaluated on the basis of how they perform at university in bodily, dispositional and emotional terms. Specifically, this includes rules on class attendance and assessment ('presenteeism'), an increasing emphasis on participation in class and in groups as part of learning and assessment regimes ('learnerism') and the surveillance of students' emotional development and values ('soulcraft'). Student performativity is symbolic of the 'performing self' in wider society and is transforming learning at university from a private space into a public performance. This negatively impacts student rights to be free to learn as autonomous adults.
\end{abstract}

Keywords: performativity; student engagement; student learning; student rights

\section{Introduction}

The term 'teacher performativity' is well known and the subject of a growing literature (e.g., Ball, 2003, 2012). This refers, inter alia, to targets, evaluations and performance indicators connected with the measurement of teaching and research quality. In a university context, academics encounter research quality assessments, student evaluation questionnaires and income generation targets. Student performativity is the mirror image of teacher performativity. It is just the targets and the performance indicators that differ. Conventionally, a student's 'performance' at university is associated with formal, individual assessments leading to the award of a degree. This requirement though now incorporates the use of contribution grading, pressure on students to participate in assessed group work exercises (both in class and online), and the requirement to perform emotionally by showing commitment to normative and personal values (e.g., global citizenship, reflection on practice). Teacher performativity is widely characterised as an unwarranted assault on the professionalism and autonomy of academics. By contrast, the growth of student performativity is generally viewed as contributing to higher levels of positive engagement.

Performativity is recognised for the way it increases academic workload in complying with audit and self-reporting procedures. It is a source of resentment and considered

\footnotetext{
*Current address: Southampton Education School, University of Southampton, Southampton, UK. Email: bmachku@gmail.com 
symbolic of the loss of trust in professionalism. Yet, this loss or lack of trust also extends to the treatment of students and can be witnessed in a variety of ways in the modern university. Examples include attendance registers, assessment-related proxies for attendance such as in-class tests and presentations, the use of anti-plagiarism software and requirements to sign statements testifying to authorship when students submit assignments for assessment.

Another ill effect ascribed to performativity is the manner in which it highlights the importance of some aspects of academic work (e.g., research output) but renders other non-audited elements almost invisible (e.g., personal tutoring or service activities) (Murray, 2012). In parallel, students are now expected to demonstrate more visibly that they are 'learning' rather than simply being offered the opportunity to attend lectures and seminars. What it means to be a student, not just the product of their intellectual endeavours undertaken in private, is now observed and evaluated.

Student performativity needs to be understood in the context of the broader performative 'turn' in society. Using a dramaturgical metaphor, Goffman (1959) identified the role of performance in social interactions and how this invariably involves impression management. Performativity is often connected with playing gender roles but it applies to any social role including, by extension, being a student. Examples are increasingly evident in communication, entertainment and the arts. Popular online social communication platforms provide opportunities to give 'networked performances' demanding skills such as improvisation, playfulness and the appearance of authenticity (Papacharissi, 2012). Crowd-based performative interaction, such as the 'Mexican wave', may be found both at sporting events and at music festivals (Sheridan, Bryan-Kinns, Reeves, Marshall, \& Lane, 2011). Visitors to museums no longer simply gaze at the exhibits; they interact in the 'participatory museum' (Simon, 2010). Alternative protest and art forms, such as flash mobs, can constitute a form of 'performative resistance' to the power of government (Walker, 2011, p. 3).

Performativity is further connected with the growing popularity of the 'confessional mode' and self-disclosure as a form of narcissism (Lasch, 1979, p. 16). Skeggs (2009) demonstrates how reality television programmes symbolise the display of self-performance in modern society identifying how participants provide a bodily, dispositional and emotional performance. Drawing on Skeggs' analysis, an analogy may be drawn with university students giving a bodily performance by attending class, or virtually via online forums; a dispositional performance through a willingness to participate in learning processes such as group work and class discussion; and an emotional performance in respect to social values and practices demanding compliance and confession, examples of which include global citizenship in the curriculum and reflection on practice. These forms of performance, labelled as presenteeism, learnerism and soulcraft, will be explored mainly in the context of an Anglo-Western cultural context. It will be argued that the effects arising from these performative pressures have a negative effect on the rights of students as autonomous adults who have entered a voluntary phase of education - to choose how to use study time, to learn as individuals, to speak or be reticent, and to develop their own ideas and values.

\section{Presenteeism}

Presenteeism is a phenomenon associated with the modern workplace and refers to employees who feel impelled to put in long working hours (Cooper, 1998, p. 314). Job insecurity and high work demands encourage employees to work even when 
they are ill (Caverley, Cunningham, \& MacGregor, 2007). While presenteeism, as the antonym of absenteeism, has attracted a good deal of interest from researchers in organisational behaviour and human resource management, there has been little consideration as to how students in higher education might be affected by this phenomenon except in relation to narrow definitions focusing exclusively on illness and depression (e.g., Law, 2007). However, universities are increasingly creating a broader culture of presenteeism through policies on attendance requirements, tasks that demand the presence of the student in order that they may be assessed during class contact time, and high levels of assessment loading.

Attendance requirements are now common in higher education institutions, enforced through a mix of institutional and departmental policies (e.g., Leufer \& Cleary-Holdforth, 2010). Punitive measures, such as excluding late arriving students from class, are also evident (e.g., Middlesex University, 2011) while electronic tracking systems have been introduced at a number of universities (e.g., Bowen, Price, Lloyd, \& Thomas, 2005). Institutions justify attendance policies on the basis of arguments related to their responsibility to be accountable to the society which funds public higher education, a concern for student welfare which might be the cause of absence from class and to develop students with an appreciation for work-related standards of behaviour, such as punctuality and reliability (Macfarlane, 2013). Hence, justifications are partly about seeking to develop students with the right 'attitudes' since non-attendance at class is identified as disrespectful to teachers and peers (University of Bolton, 2011; University of Leeds, 2011). Attendance requirements are also, to some extent, symptomatic of a crisis of confidence about the value of a higher education and a concern to demonstrate its 'value' to governments and parents as part of a performative culture (Macfarlane, 2013). The literature is dominated by claims that attendance improves student learning and completion rates (e.g., Bowen et al., 2005). However, few have questioned the performative demands of attendance requirements and their impact on students' decision-making autonomy as adults or personal freedom.

Assessment-related proxies for attendance include class contribution grading, inclass tests, examinations and oral presentations. Awarding a grade for 'contribution in class' is well established in a North American context (Bean \& Peterson, 1998) but has only become common elsewhere in the Anglosphere more recently. In a UK context, it is now not unusual for class attendance or contribution grades of between $5 \%$ and $10 \%$ to be awarded (Attwood, 2009) or even 20\% (Ni Raghallaigh \& Cunniffe, 2013). Most class contribution grades are, in effect, a grade for attendance rather than the evaluation of an individual student's actual contribution in class making it a bodily performance. Ni Raghallaigh and Cunniffe (2013) justify attendance grading on the basis of continuity of group work and appropriate preparation for the course examination. This combines the assertion that attendance is some sort of moral responsibility with pragmatic self-interest, echoing the argument about respect for peers.

Where student contribution in class is evaluated this often involves recording the number of times students get involved in activities or discussion. This is 'technically a non-achievement' rather than an authentic measure of student learning (Sadler, 2010, p. 727). Graduate teaching assistants have traditionally been used in North America to quantitatively record such information, typically based largely on oral presentations or in posing and answering questions in whole-class contexts (Long \& Bedard, 1985). Here, the performative aspects of class contribution tend to predominate criteria at the expense of more subtle, but harder to measure and less demonstrative, aspects of non-verbal engagement (e.g., active listening, note taking, etc.). 
Presenteeism is associated with occupations with high workplace and productivity demands. Here, there is a further direct parallel with a higher education context where studies have shown that exhaustion among university students is extreme even in comparison with occupations customarily associated with high work demands. In a Canadian study, university students recorded a higher exhaustion level than high-exhaustion occupations, such as social work, teaching and public accountancy (Law, 2007). Exhaustion is often associated with the over-assessment of university students (Ditcher, 2001) squeezing out time for other activities. One of the reasons for the increasing work demands faced by students is modularisation. This sub-division of learning is widely acknowledged to have led to the expansion in the volume of assessment (Bloxham \& Boyd, 2007).

\section{Learnerism}

Learnerism (Holmes, 2004) is an ideological discourse which is performative in nature by seeking to empirically analyse the results of educational achievement in terms of learning outcomes linked with the behavioural evaluation of students during the learning process. The research and discussion about teaching in higher education is narrowly focused on identifying approaches to learning, measuring their effectiveness and applying them in practice (Howie \& Bagnall, 2013). It reifies certain concepts and relies strongly on quantitative methods to prove relationships between variables (Malcolm \& Zukas, 2001). Learning is regarded as an inherently enjoyable and rewarding activity and students are expected to be devoted to their studies, keen to understand its underlying concepts in order to use a 'deep' rather than 'surface' approach to learning (Marton \& Säljö, 1976). Students should also, it is argued, seek to learn to develop the ability to self-evaluate in the process (Nichol, 2010).

Learnerist discourse is closely associated with the phrase 'student-centred learning' which suggests a focus on the needs and interests of students rather than those of the teacher (i.e., 'teacher-centred'). The phrase 'student-centred teaching' can be directly attributed to Carl Rogers (1951, p. 388). He argued that 'we cannot teach another person directly; we can only facilitate his learning' (1951, p. 389). Student-centred learning means placing students at the centre of the learning process and prioritising their needs as individuals. Teaching in a 'student-centred' manner is normally assumed to incorporate expectations that students actively 'engage' and 'manage' their own learning. Being teacher-centred means the teacher has authority as the expert to communicate a specialist body of knowledge to students in a style in which he or she sees fit. This normally implies the use of the lecture method in which the predominant role of the student is to listen while the teacher talks (Mascolo, 2009).

The performative expectations of a student-centred approach are justified on the basis of a social constructionist philosophy which interprets knowledge development as an individualised process in understanding the world. Learnerism emphasises the need for the student to be publicly 'seen' to be learning and constructing a personal understanding instead of acquiring knowledge as a private activity. The learner is 'a do-er of learning' (Holmes, 2004, p. 627). The role of the teacher is, therefore, to facilitate student development rather than 'teach' objective knowledge as, if one accepts a social constructionist perspective, everyone constructs their own version of the truth. The authoritative role of the teacher is challenged and, in the process, the importance of students constructing understanding of knowledge for themselves is sometimes confused with them entering into 
this process by themselves (Mascolo, 2009, p. 7). According to the literature, the role of the teacher should be to encourage students to become deep rather than surface learners. The censorious nature of phrases such as 'teacher-centred' and 'surface learning' imply, in effect, 'bad' teaching (or learning) means that it is unfashionable to question the assumptions of learnerism or the performative demands that follow. Curiously, while the phrase 'student-centred' implies a self-conscious focus on the needs of students, the negative effects of participative techniques have tended to be overridden by arguments focused on the benefits students derive from achieving certain learning outcomes.

There is a wealth of evidence that students prefer to learn in ways that are often labelled negatively as 'traditional' or 'passive', notably via the lecture method. In a study of 15,000 undergraduate students across several Canadian universities, Fusaro and Couture (2012) found that students prefer lectures to discussion-based activities if they are engaging and relevant. The research also shows that instructors overestimate the extent to which students prefer this latter approach. This means that while the literature emphasises the superiority of active learning, students still rate lectures very highly and find elements of active learning, such as the time-consuming nature of these activities and the fear that they will not be able to cover the course material, disconcerting. Students like lectures to be interactive and engaging, defined in a relatively limited sense as one in which the teacher makes a set presentation, students listen and take notes and then have the opportunity to ask questions and perhaps undertake exercises to check progress (Sander et al., 2000). They hope for, or prefer, an interactive lecture to other approaches such as student-centred teaching and group work. Learnerists advocate peer learning as a valuable means by which institutions may 'focus their efforts primarily on developing in students the ability to critically evaluate the quality and impact of their own work ...' (Nichol, 2010, p. 7). Yet students with predispositions to work alone can perceive periods spent in discussion with peers as poor value for time and resent listening to ill-informed and dominating classmates (Hancock, 2004).

Ironically, the skills required to succeed at university, and beyond, may run counter to assumptions that deep, conceptual approaches to learning are superior to surface or strategic approaches. Time management is a critical skill in the modern, information age with 'fast' time driving out 'slow' time (Eriksen, 2001). Fast time refers to the displacement of time as a linear concept with 'stacking', involving simultaneous actions and processes. The ability of individuals to manage this 'time tyranny', as Eriksen labels it, has become critical in a society which values efficiency above all else. Students (and academics) must cope with the demands of information overload in the same way as anyone else in modern society. As a result, rather than adopting a conceptual approach to learning, students more readily identify an approach to learning based on their management of time. This can be represented as either 'being in control' or 'being out of control' of time (Case \& Gunstone, 2003, p. 55). Students regard efficient time management as the most critical factor in determining their success. Undertaking activities involving deep understanding are often perceived to take up too much time and decision-making depends 'first and foremost on whether the task counted for marks and how much' (Case \& Gunstone, 2003, p. 62). This strongly suggests that students approach learning in what is termed a 'strategic' way designed to maximise personal achievement (Entwistle \& Ramsden, 1983; Kneale, 1997). A strategic approach to learning, however, is really a variation on a surface approach since it is not principally focused on a deep conceptual engagement. The power of the deep/surface metaphor has led to the negative labelling and 'blaming' of students for using the 'wrong' 
approach (Case \& Gunstone, 2003). Yet, a surface approach to learning, making discriminatory choices in the face of time pressure, is a vital skill in the modern world.

Learnerism treats issues of fairness as subsidiary to the efficiency and effectiveness of learning processes. This contrasts with an understanding of student-centredness from a student rights perspective. Assessing group work provides an example of this tension. Despite the learning benefits frequently cited in the literature, students often view working and learning with others on group tasks in a negative light (e.g., Ni Raghallaigh \& Cunniffe, 2013; Pfaff \& Huddlestone, 2003) and are concerned about the fairness of group grading (Volet \& Ang, 1998). Whether groups free form or are moulded by the intervention of the teacher is a key issue and there is a noted tendency for home and international student clusters to segregate where groups free form without direction from the teacher (Wang, 2012). Group processes are frequently justified because they are said to represent a simulacrum of how people work together in the 'real' world. They are considered as self-evidently justified on this basis. Yet, this analogy does not acknowledge the role of hierarchical relations in the workplace exacting control over group members and aiding motivation for all individuals to contribute to tasks. This makes it much more difficult for a team member to free-ride in the workplace. By contrast, on a university campus, all members of a group or team are peers without a hierarchical structure or reward and punishment mechanisms available to a group leader. This makes free-riding much more likely especially if teachers fail to identify individual contributions to group tasks or allow groups to free form (Pfaff \& Huddlestone, 2003). While strategies exist to make group-work assessment fairer, it needs to be recognised that the popularity of this approach among many rank and file professors rests on the pragmatic perception that it will reduce their workload rather than improve student learning (Livingstone \& Lynch, 2000).

Class discussion is another element of the dispositional performance expected of students which is core to learnerist approaches emphasising the importance of the social construction of knowledge. While class discussion can prove popular among students and beneficial to their development of work-related skills it is also something which can cause underestimated levels of discomfort. In a study of audience response systems at university, $47 \%$ of students were reluctant to share their own opinions publicly in class (Graham, Tripp, Seawright, \& Joeckel, 2007, p. 245). While teachers often assert that they make an effort to emphasise that student opinions are welcome and will not be judged as to whether they are 'right' or 'wrong' (e.g., Ni Raghallaigh \& Cunniffe, 2013), this is essentially a teacher-centric perspective on creating a 'safe' learning environment. It does nothing to remove student fears that they may be embarrassed in front of, or subject to criticism from, peers. One of the other consequences of asking students in a large class to learn collaboratively is that it forces them to lose their anonymity (Machemer \& Crawford, 2007, p. 24). While confidentiality and anonymity are considered paramount in thinking about research ethics, such considerations are almost never extended to students learning in the classroom despite their vulnerability. These are all reasons why students report feelings of anxiety and insecurity when teaching is organised in an avowedly student-centred way (Lea, Stephenson, \& Troy, 2003).

A commitment to student-centred learning is now a rhetorical boast made by nearly all universities. This mantra may be found in university engagement policies that emphasise the need for students to participate actively in class rather than being passive (e.g., Penn State University, 2013). Few, if any, of these policies though define what is meant by 'participate actively'. What this often implies in practice is that a student has no right to reticence or silence and must 'speak up' regardless of 
whether they are comfortable to do so. This has the effect of negatively labelling nonoral participation, such as eye contact, note taking and active listening, as 'passive'. Those who attend seminars but remain silent or fail to participate in online learning communities more specifically are referred to as 'lurkers' (Nonnecke \& Preece, 2000). This judgemental label applies to individuals who read and observe but stay silent. Lurkers are seen as a problem because they are branded as selfish, non-contributors who take without giving to the learning community. However, this impression is based, to a large extent, on Anglo-Western assumptions about the dialogic nature of the social construction of knowledge. Such assumptions have been applied to students from Confucian-heritage cultures with little attention to cultural values in these contexts. Grading oral participation in class ignores a student's 'right to reticence' (Chanock, 2010) and the role of silence in learning among Chinese learners (Jin, 2012). In Chinese culture being quiet and introspective demonstrates sensitivity and understanding (Cain, 2012). Many Western students also prefer silence to sharing (Cain, 2012) and it is notable that Rogers gave his own students the choice to talk or be silent (1951, p. 395). Assessing participation represents an authoritarian turn alien to Rogers' founding liberating intent that students should enjoy 'freedom from pressure' (1951, p. 395).

\section{Soulcraft}

The mission statements of universities invariably refer to their desire to turn their students into 'good citizens' or 'future leaders' (Astin, 2002). While such declarations involve marketing hyperbole, they also indicate how universities ascribe to themselves a legitimate role as moulders or shapers of student belief systems. This is about an attempt to govern the soul (Rose, 1990). Universities, especially those with religious roots, have always been involved in civic and spiritual soulcraft to some extent. Historically this was connected with the founding philosophy of higher education institutions and system-wide religious tests operated until the late nineteenth century in English universities. Contemporary soulcraft is more secular and covert in nature. Two prominent examples illustrate the influence of soulcraft ${ }^{1}$ in the curriculum: globalism and reflective writing or reflectivity. The former refers to, and can be found prominently in, the undergraduate curriculum while the latter is principally associated with postgraduate education.

Globalisation is a normative and ideologically charged concept based on a multitude of competing explanations and claims traversing the political left and right (Steger, 2009). On the right, market globalism interprets globalisation as evidence of the pre-eminence of neo-liberal forces such as free trade, privatisation and the weakness of the nation-state to control the boundaries of commerce. On the political left, a different interpretation of globalisation prevails which Steger (2009) coins justice globalism. This stresses a social justice agenda which can only be achieved through global cooperation and encompasses the elimination of poverty, more equitable income distribution, international human rights and the protection of the environment. The Clinton Global Citizen Awards, established in 2007 by the former US President, is symbolic of the importance attached to action-oriented social change valued by those allied to this position. The values of justice globalism centre on collectivism and social activism, whereas market globalism is about laissez faire neo-liberal individualism.

The phrase 'global citizenship' is widely invoked particularly in educational contexts. Understandings of globalism relate directly to this phrase. When questioned, 
student understanding of global citizenship appears squarely aligned with the claims of justice globalism. In a study of Canadian student perspectives about global citizenship, inequality was identified as the most common concern along with other issues such as poverty, gender inequity, sustainability, the environment and human rights (Roddick, 2007). The dominance of justice globalism is hardly surprising given the long history and influence of service learning, education for action and other community engagement projects on university campuses. These are areas of activity strongly related to the claims of social justice and the perceived role of the university in promoting such ends. Student perspectives are further shaped by the growth of citizenship education in schools internationally with leading charities, such as Oxfam, supporting 'active' global citizenship materials for schools (Oxfam, 2013).

Universities also interpret globalism in terms of a social justice and an actionoriented agenda. This may be observed in curriculum and extra-mural activities often within university general education and elective programmes. The World University Service of Canada (WUSC) supports what is termed a 'Global Citizens for Change' initiative while in the UK and Australia many universities have developed sets of graduate attributes which contain explicit expectations that students will become advocates of global citizenship (Barrie, 2004). At the University of Sydney global citizenship is one of three 'holistic, overarching attributes' (Barrie, 2004, p. 271) required of undergraduate students along with scholarship and lifelong learning. A similar emphasis on global citizenship can also be found at other Australian universities such as Melbourne and Deakin. Influenced by Australian examples, global citizenship is one of several graduate attributes identified across Scottish universities and has been encouraged by the Quality Assurance Agency for Higher Education in Scotland as part of a curriculum enhancement project (Hounsell, 2011). At the University of Hong Kong, one of the four goals of the common core curriculum is to "enable students to see themselves as members of global as well as local communities and to play an active role as responsible individuals and citizens in these communities' (University of Hong Kong, 2012, np). Such statements can be found at a large number of other universities on an international basis.

The effect of the promotion of globalism, as with other elements of soulcraft, needs to be understood in the context of research which has shown that shyness, a lack of preparation for discussion and fear of contradicting the views of the professor can lead students to self-censor when asked to discuss value-based concepts such as multiculturalism (Hyde \& Ruth, 2002). Rather than appear uncaring or selfish students must provide an emotional performance to demonstrate their commitment to globalism.

A different sort of emotionally laden performance is required in connection with reflective writing which has become an important element of student assessment in postgraduate professional and vocational courses. Reflective diaries and portfolios are now an established part of nursing, teaching, architecture and even accountancy courses, influenced by the work of Schön (1983). As one of the key concepts of teacher training in higher education (Kandlbinder \& Peseta, 2009), it is a key part of an attempt to 'change academics' approaches to teaching from being teacher-focused to being more student-focused' (Hanbury, Prosser, \& Rickinson, 2008, p. 480). Reflection on practice is also an integral part of Personal Development Planning, an initiative affecting all UK higher education students, not just postgraduates. Hence, the influence of reflection is widespread.

While reflective writing is intended to provide an authentic insight into the links between professional theory and practice and the inner thought processes of students, 
assessing them in this way brings to the fore performative rituals of confession and compliance (Ross, 2011). Students must display a range of emotional responses in their reflective writing: penitence for past mistakes or lifestyle choices, excitement at discovering some gratitude for the way the process has 'transformed' their lives. Many students are strategic in knowing what the teacher's preferences are and are 'audience-aware' in the manner in which they produce reflective writing for a number of different readers (Ross, 2012). This is an example of the performing self in a similar mould to the reality television contestant (Macfarlane \& Gourlay, 2009) and represents the 'surveillance of students' emotional and developmental expression' (Ross, 2011, p. 113).

\section{The performative environment}

A growing emphasis on student performativity, particularly presenteeism and learnerism, needs to be understood in the context of the rise in the student engagement movement. Mass higher education systems are associated with high levels of non-completion and student engagement initiatives are intended, in part, to improve student completion and success rates at university. Many higher education institutions now have such a programme in place such as The Student Success Program at the Queensland University of Technology in Australia. This is designed to identify and support those students deemed to be 'at risk of disengaging from their learning and their institution' (Nelson, Quinn, Marrington, \& Clarke, 2012, p. 83).

Student engagement implies a learning environment where participants, drawn from diverse backgrounds, are actively engaged in a participatory culture and experience an adequately resourced and interactive approach to teaching (Newswander \& Borrego, 2009). Hence, student engagement has a behavioural dimension which demands in-class participation. It also has an emotional element in the way that students are expected to relate to others and to their learning environment and, finally, a cognitive dimension representing how students should construct their own understanding and learn how to learn more effectively (Fredricks, Blumenfeld, \& Paris, 2004). In short, students must demonstrate that they are 'invested participants' (Conrad \& Haworth, 1997, p. 553). This implies a commitment to performative values such as learning cooperatively with peers, sharing their ideas in public forums and being prepared to take part in community-based projects, another illustration of soulcraft which requires students to demonstrate that they share the normative values of social justice.

The assumptions that inform student engagement are that anything that gets students more involved in participating at university is a good thing. It makes the process of learning more communal and, furthermore, is underpinned by the pragmatic arguments that if students are engaged as learners they are more likely to complete their studies, obtain better degree results and gain life skills suitable for the employment market (e.g., Allen, 1999; Astin, 1993; Kuh, Cruce, Shoup, Kinzie, \& Gonyea, 2008). Hence, student engagement theory and university initiatives see performativity in a positive light as contributing to learning and improving completion rates rather than recognising the anti-libertarian implications of performativity.

The rise of student performativity may, in part, be explained by the expansion of vocationally oriented subjects within the university curriculum placing more emphasis on the public testing of professional skills and the development of behavioural values associated with the workplace. Arguments in respect to preparation for the workplace 
underscore presenteeism while a similar rationale is often used to justify elements of learnerism, such as working as a member of a team. Elements of soulcraft, such as reflective writing, are also principally associated with professional and vocational programmes.

\section{Conclusion}

In complying with the demands of performativity, academics and students need to do so in word as well as deed. It requires a casting aside or suppression of personal views and demands a 'playing of the game'. Performative environments encourage inauthentic behaviour as individuals endeavour to conform. Those who resist by refusing to 'play the game' are subtly disadvantaged. Academics fail to gain promotion or are punished in other ways, such as being excluded from research quality assessment. Students who remain silent in seminars or do not participate sufficiently in online learning communities risk being derided as 'lurkers'. Those that seek to resist the demands of soulcraft risk being labelled uncaring or insufficiently reflective. The personal has become the public.

Presenteeism removes the right of students to be treated as adults and exercise free choice retarding their opportunity to develop this capacity in the process. Learnerism subjects students to participative pressures turning university study as a private space into a mode of observable public performance. While students have concerns about the efficient use of time, fairness (e.g., group-work assessment) and privacy (e.g., loss of anonymity through forced participation in large classes and sharing opinions in class), learnerists see these matters as subsidiary problems to be overcome by better teaching strategies rather than taking priority over the quantification of learning outcomes. Finally, soulcraft demands an oral and textual enactment of the private and personal, domesticating rather than empowering students as free and independent thinkers. Hence, being 'student-centred' needs to be understood from a student rights perspective rather than purely in terms of the efficiency and effectiveness of their learning. More research into performativity is needed from a student rather than a teacher perspective and much greater critical attention needs to be paid to the impact of the engagement agenda on the freedom to learn.

\section{Note}

1. The term 'soulcraft' has also been used, quite differently, to mean the intrinsic pleasure derived from skilled labour.

\section{References}

Allen, D. (1999). Desire to finish college: An empirical link between motivation and persistence. Research in Higher Education, 40(4), 461-485.

Astin, A.W. (1993). What matters in college? Four critical years revisited. San Francisco, CA: Jossey-Bass.

Astin, A.W. (2002). Higher education and the cultivation of citizenship. In D. Allman \& M. Beaty (Eds.), Cultivating citizens (pp. 91-102). Lanham, MD: Lexington Books.

Attwood, R. (2009, September 10). Thanks very much for coming: You shall be rewarded. The Times Higher Education Supplement, p. 6.

Ball, S. (2003). The teacher's soul and the terrors of performativity. Journal of Education Policy, 18(2), 215-228. 
Ball, S. (2012). The making of a neoliberal academic. Research in Secondary Education, 2(1), 29-31.

Barrie, S.C. (2004). A research-based approach to generic graduate attributes policy. Higher Education Research \& Development, 23(3), 261-275.

Bean, J.C., \& Peterson, D. (1998). Grading classroom participation. In R.S. Anderson \& B.W. Speck (Eds.), Changing the way we grade student performance: Classroom assessment and the new learning paradigm (pp. 33-40). San Francisco, CA: Jossey-Bass.

Bloxham, S., \& Boyd, P. (2007). Developing effective assessment in higher education: A practical guide. Maidenhead: Open University Press.

Bowen, E., Price, T., Lloyd, S., \& Thomas, S. (2005). Improving the quantity and quality of attendance data to enhance student retention. Journal of Further and Higher Education, 29(4), 375-385.

Cain, S. (2012). Quiet: The power of introverts in a world that can't stop talking. London: Penguin.

Case, J., \& Gunstone, R. (2003). Going deeper than deep and surface approaches: A study of students' perception of time. Teaching in Higher Education, 8(1), 55-69.

Caverley, N., Cunningham, J.B., \& MacGregor, J.N. (2007). Sickness presenteeism, sickness absenteeism, and health following restructuring in a public service organization. Journal of Management Studies, 44(2), 304-319.

Chanock, K. (2010). The right to reticence. Teaching in Higher Education, 15(5), 543-552.

Conrad, C.F., \& Haworth, J.G. (1997). Emblems of quality in higher education: Developing and sustaining high-quality programs. Boston, MA: Allyn and Bacon.

Cooper, C.L. (1998). The changing nature of work. Community, Work and Family, 1(3), 313-317.

Ditcher, A.K. (2001). Effective teaching and learning in higher education, with particular reference to the undergraduate education of professional engineers. International Journal of Engineering Education, 17(1), 24-29.

Entwistle, N.J., \& Ramsden, P. (1983). Understanding student learning. Beckenham: Croom Helm.

Eriksen, T.H. (2001). Tyranny of the moment: Fast and slow time in the information age. London: Pluto Press.

Fredricks, J.A., Blumenfeld, P.C., \& Paris, A.H. (2004). School engagement: Potential of the concept, state of the evidence. Review of Educational Research, 74(1), 59-109.

Fusaro, M., \& Couture, A. (2012). Étude sur les modalités d'apprentissage et les technologies de l'information et de la communication dans l'enseignement. Quebec: Conference Des Recteurs Et Des Principaux Des Universités Du Québec.

Goffman, E. (1959). The presentation of self in everyday life. New York: Doubleday.

Graham, C.R., Tripp, T.R., Seawright, L., \& Joeckel, G.L. (2007). Empowering or compelling reluctant participators using audience response systems. Active Learning in Higher Education, 8(3), 233-258.

Hanbury, A., Prosser, M., \& Rickinson, M. (2008). The differential impact of UK accredited teaching development programmes on academics' approaches to teaching. Studies in Higher Education, 33(4), 469-483.

Hancock, D. (2004). Cooperative learning and peer orientation effects on motivation and achievement. The Journal of Educational Research, 97(3), 159-166.

Holmes, L. (2004). Challenging the learning turn in education and training. Journal of European Industrial Training, 28(8/9), 625-638.

Hounsell, D. (2011). Graduates for the 21st century: Integrating the enhancement themes. Glasgow: Quality Assurance Agency for Higher Education. Retrieved October 12, 2013, from http://www.enhancementthemes.ac.uk/

Howie, P., \& Bagnall, R. (2013). A critique of the deep and surface approaches to learning model. Teaching in Higher Education, 18(4), 389-400.

Hyde, C.A., \& Ruth, B.J. (2002). Multicultural content and class participation: Do students selfcensor? Journal of Social Work Education, 38(2), 241-256.

Jin, J. (2012). Sounds of silence: Examining silence in problem-based learning (PBL) in Asia. In S. Bridges, C. McGrath, \& T. Whitehill (Eds.), Problem-based learning in clinical education: The next generation (pp. 171-185). Dordrecht: Springer. 
Kandlbinder, P., \& Peseta, T. (2009). Key concepts in postgraduate certificates in higher education teaching and learning in Australasia and the United Kingdom. International Journal for Academic Development, 14(1), 19-31.

Kneale, P. (1997). The rise of the 'strategic student': How can we adapt to cope?. In S. Armstrong, G. Thompson, \& S. Brown (Eds.), Facing up to radical changes in universities and colleges (pp. 119-130). London: Kogan Page/SEDA.

Kuh, G.D., Cruce, T.M., Shoup, R., Kinzie, J., \& Gonyea, R.M. (2008). Unmasking the effects of student engagement on first-year college grades and persistence. Journal of Higher Education, 79(5), 540-563.

Lasch, C. (1979). The culture of Narcissism: American life in the age of diminishing expectations. London: Norton Press.

Law, D.W. (2007). Exhaustion in university students and the effect of coursework involvement. Journal of American College Health, 55(4), 239-245.

Lea, S.J., Stephenson, D., \& Troy, J. (2003). Higher education students' attitudes to studentcentred learning: Beyond 'educational bulimia'? Studies in Higher Education, 28(3), $321-334$.

Leufer, T., \& Cleary-Holdforth, J. (2010). Reflections on the experience of mandating lecture attendance in one school of nursing in the Republic of Ireland. All Ireland Journal of Teaching and Learning in Higher Education, 2(1), 18.1-18.14.

Livingstone, D., \& Lynch, K. (2000). Group project work and student-centred active learning: Two different experiences. Studies in Higher Education, 25(3), 325-345.

Long, D.D., \& Bedard, J.C. (1985). Evaluation of a discussion technique used for both classroom instruction and grade assignment. American Journal of Physics, 53(5), 401-404.

Macfarlane, B. (2013). The surveillance of learning: A critical analysis of university attendance policies. Higher Education Quarterly, 67(4), 358-373.

Macfarlane, B., \& Gourlay, L. (2009). The reflection game: Enacting the penitent self. Teaching in Higher Education, 14(4), 455-459.

Machemer, P.L., \& Crawford, P. (2007). Student perceptions of active learning in a large crossdisciplinary classroom. Active Learning in Higher Education, 8(1), 9-30.

Malcolm, J., \& Zukas, M. (2001). Bridging pedagogic gaps: Conceptual discontinuities in higher education. Teaching in Higher Education, 6(1), 33-42.

Marton, F., \& Säljö, R. (1976). On qualitative differences in learning: Outcome and process. British Journal of Educational Psychology, 46(1), 4-11.

Mascolo, M.F. (2009). Beyond teacher- and learner-centered pedagogy: Learning as guided participation. Pedagogy and the Human Sciences, 1(1), 4-27.

Middlesex University. (2011). Attendance (pre-registration nursing and midwifery) policy. Retrieved March 14, 2012, from unihub.mdx.ac.uk/Assets/attendance.docx

Murray, J. (2012). Performativity cultures and their effects on teacher educators' work. Research in Teacher Education, 2(2), 19-23.

Nelson, K.J., Quinn, C., Marrington, A., \& Clarke, J.A. (2012). Good practice for enhancing the engagement and success of commencing students. Higher Education, 63(1), 83-96.

Newswander, L.K., \& Borrego, M. (2009). Engagement in two interdisciplinary graduate programs. Higher Education, 58(4), 551-562.

Nichol, D. (2010). The foundation for graduate attributes: Developing self-regulation through self and peer assessment. Glasgow: The Quality Assurance Agency for Higher Education Scotland. Retrieved July 8, 2012, from www.enhancementthemes.ac.uk

Ni Raghallaigh, M., \& Cunniffe, R. (2013). Creating a safe climate for active learning and student engagement: An example from an introductory social work module. Teaching in Higher Education, 18(1), 93-105.

Nonnecke, B., \& Preece, J. (2000). Lurker demographics: Counting the silent. Proceedings of CHI 2000. The Hague: ACM.

Oxfam. (2013). Global citizenship. Retrieved December 12, 2013, from http://www.oxfam.org. uk/education/global-citizenship

Papacharissi, Z. (2012). Without you, I'm nothing: Performances of the self on twitter. International Journal of Communication, 6. Retrieved April 17, 2013, from http://ijoc. org/ojs/index.php/ijoc/article/view/1484

Penn State University. (2013). Principles of student participation in academic affairs. Retrieved November 19, 2013, from http://senate.psu.edu/policies/index.html 
Pfaff, E., \& Huddlestone, P. (2003). Does it matter if I hate teamwork? What impacts student attitudes towards teamwork. Journal of Marketing Education, 25(1), 37-45.

Roddick, M. (2007). Global citizenship perspectives: A case study of the WUSC international seminar. Retrieved March 21, 2012, from devcase.org/documents/global-citizenshipperspectives.pdf

Rogers, C. (1951). Client-centered therapy: Its current practice, implications and theory. London: Constable.

Rose, N. (1990). Governing the soul: The shaping of the private self. London: Routledge.

Ross, J. (2011). Traces of self: Online reflective practices and performances in higher education. Teaching in Higher Education, 16(1), 113-126.

Ross, J. (2012). Performing the reflective self: Audience awareness in high-stakes reflection. Studies in Higher Education, 39(2), 219-232.

Sadler, D.R. (2010). Fidelity as a precondition for integrity in grading academic achievement. Assessment and Evaluation in Higher Education, 35(6), 727-743.

Sander, P., Stevenson, K., King, M., \& Coates, D. (2000). University students' expectations of teaching. Studies in Higher Education, 25(3), 309-323.

Schön, D.A. (1983). The reflective practitioner. New York: Basic Books.

Sheridan, J., Bryan-Kinns, N., Reeves, S., Marshall, J., \& Lane, G. (2011). Graffito: Crowdbased performative interaction at festivals (pp. 1129-1134). Proceedings of CHI conference on human factors in computing systems, Vancouver, BC, Canada. New York: ACM.

Simon, N. (2010). The participatory museum. Santa Cruz, CA: Museum.

Skeggs, B. (2009). The moral economy of person production: The class relations of self-performance on "Reality" television. The Sociological Review, 57(4), 626-644.

Steger, M.B. (Ed.). (2009). Globalisms. Lanham, MD: Rowman and Littlefield Publishers Inc.

University of Bolton. (2011). Student attendance policy. Retrieved September 18, 2012, from http:// www.bolton.ac.uk/Students/PoliciesProceduresRegulations/AllStudents/Documents/ StudentAttendancePolicy.pdf

University of Hong Kong. (2012). Common core. Retrieved August 28, 2013, from http:// commoncore.hku.hk/global-issues/

University of Leeds. (2011). Attendance monitoring - Policy, guidance and examples of good practice for schools. Retrieved April 14, 2012, from http://www.leeds.ac.uk/rsa/ admissionsandregistration/forstaff/attendance.html

Volet, S., \& Ang, G. (1998). Culturally mixed groups on international campuses: An opportunity for inter-cultural learning. Higher Education Research \& Development, 17(1), 5-23.

Walker, R.A. (2011). Badgering big brother: Spectacle, surveillance, and politics in the flash mob. Liminalities: A Journal of Performance Studies, 7(2), 1-23.

Wang, Y. (2012). Mainland Chinese students' group work adaptation in a UK business school. Teaching in Higher Education, 17(5), 523-535. 